[Penultimate DRAFt. Please Cite The PUblished Version:

Journal of the American Philosophical Association 3 (3):265-283]

\title{
Personal Ideals as Metaphors
}

\author{
Nick Riggle \\ University of San Diego
}

\begin{abstract}
What is it to have and act on a personal ideal? Someone who aspires to be a philosopher might imaginatively think 'I am a philosopher' by way of motivating herself to think hard about a philosophical question. But doing so seems to require her to act on an inaccurate self-description, given that she is not yet what she regards herself as being. J. David Velleman develops the thought that action-by-ideal involves a kind of fictional self-conception. My aim is to expand our thinking about personal ideals by developing another way of understanding them. On this view action-by-ideal involves a kind of metaphorical self-conception. I investigate some salient differences between these views with the aim of understanding the different perspectives they take on the rationality of action-by-ideal. Where the fiction view runs into problems of literary coherence, the metaphor view exploits the richness of poetic invention. But action-byideal is a complex phenomenon about which there may be no tidy story to be told. This paper is an attempt to clarify and understand more of this messy terrain.
\end{abstract}

\section{Introduction}

Sometimes I like to think I am a philosopher. But am I? I can also be genuinely dumb. I make bad arguments, think absurdly scattered thoughts, have the wrong emotional responses, get confused, express undue irritation, begin philosophy papers with weird lists, and would much rather lose myself in elementary pleasures than think about the nature of anything. Actually, not just sometimes - lots of times, as in, this is a regular feature of my life. And I suspect it will be for a while still. Am I a philosopher? ${ }^{1}$

\footnotetext{
' I am in fact a philosophy professor, but that is neither necessary nor sufficient for being a philosopher in the sense that might be someone's personal ideal. What sense is that? It is not that I want to be a
} 
I want to be. Look at me writing papers like this, thinking about what it means to think I am something I know full well I regularly am not. But some days I think, I am a philosopher, and it is just so right, even though I am as sure of the cogito as I am that I regularly fall short. And when I do fall short, I sometimes think to myself I am a philosopher. There are times when the thought seems cruel or unloving; but sometimes it sings - I sit down in my armchair, furl my brow, and get to thinking.

Sometimes our actions are motivated by our identifying with an ideal-self-conception (or for simplicity, an ideal), and our ideals seem to be inaccurate self-conceptions. ${ }^{2}$ In contemplating and acting on an ideal, we seem to contemplate the thought that we are what we ideally are, even though we are not. Yet we normally consider people who think of themselves under inaccurate conceptions to be deluded at best, insane at worst. We worry about the disheveled man who claims he's king. Why don't we similarly worry about the fledgling art student who whispers to herself, "I am an artist" and carries on? She seems to be even worse off than the purported king, for she knows, or at least reasonably suspects, that she is not yet what she regards herself as being. What are personal ideals, and how do they move us to act?

philosopher through and through, nor is it that I want to be a good philosopher. It is that I want to be an excellent philosopher, by my lights.

${ }^{2}$ My talk of ideals refers to ideal-self-conceptions throughout. A conception of something is a way of regarding it as $F$, for some $F$. So a self-conception is a way of regarding oneself as $F$. An ideal self-conception, then, is a way of aspirationally regarding oneself as $F$, while believing to some degree that one is not $F$. A central question in this paper is what this kind of 'regard' amounts to. I am not interested in narrowly moral ideals, but in broadly personal ideals, or ideals of the kind person we are or the kind of life we live. These conceptions can be more or less filled out. Sometimes they are rather thin or minimal. Other times they are more complex. I begin by considering relatively thin ideals and later consider more complex or multifaceted (and I believe true-to-life) ideals. 
In several papers, J. David Velleman develops the thought that ideals are a kind of fictional self-conception (see especially Velleman 2006a but see also 2006b, c, and 2000). On Velleman's view, acting to realize an ideal is acting to realize a fictional self-image. 'Acting out of identification with an ideal is like a game of make-believe, in which we pretend to be that with which we identify.' (2006a: 313) You pretend - you accept as (fictionally) true - that you are this kind of person, and you aim to enact the pretense. On this view, the student's saying 'I am an artist' is like saying of a stump 'This is a bear' in a game of make-believe. Acting to realize an inaccurate self-conception is, in this way, like acting as a character in a play, except the play is your life. If all goes well, then you will become your character.

There is very little in the philosophical literature about the nature and moral psychology of personal ideals (for insightful general claims about personal ideals, see Anderson (1993); for a discussion of pride and personal ideals, see Fischer (2012); and see especially Callard (2016)). Velleman's fiction view of personal ideals is promising, but action-by-ideal seems far messier than this and in need of further exploration. In what follows, I consider Velleman's view and develop an alternative model. On this model, ideals are metaphors. Thinking of oneself as a philosopher, under the guise of an ideal, is like thinking of Juliet as the sun, under the influence of love. I begin by spelling out some of the details of Velleman's view and drawing out a few important consequences of it (section 1). I then argue for a distinction between fictional and metaphorical imagination (section 2) and introduce the view of ideals as metaphors (section 3). I then detail a range of differences between the two views (section 4) by way of arguing that metaphorical ideals can play a role in rational action that Velleman denies of fictional ideals (section 5). My hope is that we can come to appreciate how metaphor might play a central and rational role in our being the kind of person we aspire to be. 


\section{Ideals as Fictions}

Perhaps the simplest proposal about personal ideals is to say that they are descriptions of people we wish to resemble; our desire to resemble them motivates behavior we take to be characteristic of them in conjunction with various beliefs we have about how to achieve the resemblance. But as Velleman notes, the simple proposal is a nonstarter (2006a: 325-26). Such a view construes the motivational force of ideals as issuing from a desire to resemble. This has the consequence that one's ideal-motivated behavior will always fail to resemble the ideal, for the kind of person one wants to resemble is not motivated by a desire to resemble- she is the real deal (unless you idealize resemblers, but then the problem iterates).

Consider for example someone who idealizes generous people. If she thought that the way to attain her ideal is to act like a generous person, then her actions would be motivated not by generosity but by the desire to be like a generous person. But a truly generous person is not acting on such a motive. So our envisioned actor, even if she succeeds in acting generously, would fail to be a generous person; she would always fall short of her ideal. This is not to deny that one might be able to become generous, perhaps over time, by acting like or imitating a generous person. There are many ways to try to become the type of person one wants to become, and imitation is certainly among them. But there is more to action-by-ideal than action-byimitation.

Velleman's alternative to the simple proposal begins with the thought that we need to make use of the imagination. He writes,

The desire to mold oneself in the image of a generous person will meet with better success

if it moves one first to imagine being a generous person and then to enact this self-image, making believe that one is generous and using as props whatever motives one has that can be cast in the role of generosity.(2006a: 326) 
On Velleman's view, having and acting on an ideal involves imagining being the kind of person we idealize. And our imaginings play a role in our making believe that we are such a person, not that we resemble them. We succeed when we really are what we imagine ourselves to be through make-believe. Make-believe is of course most familiar from children's play, where sticks are guns, cardboard boxes are castles, and sidewalk cracks are vast ravines.

Velleman holds that make-believe involves actively employing mock-beliefs (see Velleman [2000]; mock-beliefs are 'mock'-beliefs because they have the same motivational role as beliefs but, unlike them, are not held with the aim of getting their truth-value right). When the enthusiastic sports fan yells at the ref on television, she does not do so believing that the ref will take her opinion into consideration. She does not really believe she will succeed because she knows she's only imagining that the referee can hear her. Her imagining plays the motivational role of belief when it combines with her desire to yell at the ref. Of course, the enthusiastic sports fan is not (normally) enacting an ideal; her imagination is issuing mental states that play the motivational role of beliefs so that she can express herself, playing along with the real audience. In this way, her mock-belief plays an instrumental role in motivating action. On Velleman's view, the mockbeliefs involved in action-by-ideal play a different motivational role, by entering into our actionguiding self-conceptions and altering the way we understand our various motives, beliefs, commitments, and so on.

Thus, on Velleman's view, when the philosophy student thinks 'I am a philosopher' she is entertaining a fictional truth. She accepts in a sense that she is a philosopher, but she accepts it under the aegis of fiction. The sense in which her self-conception is inaccurate is the sense in which it is inaccurate to say, literally, that a stick is a gun. If challenged, she need not offer a defense. She might retreat from the fiction and say, 'Oh, no I am pretending; do not hold me to account. Of course, if you were to play along and treat me as a philosopher, I would not 
complain.' Getting others to play along might be the very thing that nudges her fiction into reality and makes her action-by-ideal ultimately successful.

As a result, what 'I' refers to in the idealized 'I am a philosopher' cannot be what 'I' refers to outside of the fiction, that is, her actual self. For she knows that she is not a philosopher, and as a good epistemic agent, she does not want to sincerely think something that she knows to be so false. Nor would keeping her actual self in mind be conducive to success in action-by-ideal — the novice has to focus on the task of becoming a master, not constantly remind herself that she is not.

Normally when we consciously refer to ourselves in the first-person we take ourselves to be referring to something about which we have collected a trove of information - from boring facts about daily minutia, to facts about life's more exciting crescendos and complications.

Normally we take 'I' to pick out the thing described by our self-notion, the thing that:

SN: $\quad$ had coffee with his wife this morning; lives in the San Diego; is married to Brett; loves art; makes music and writes fiction; loves skating; makes bad arguments sometimes; sometimes would rather watch TV than do philosophy; teaches philosophy to college students; loves thinking; enjoys considering different perspectives; relishes a good argument; loves cooking for his friends; and so on.

What 'I' refers to in our fictional ideals is like what 'this' refers to when we say 'This is a gun!' while referring to a stick in a game of make-believe cops and robbers. In doing so we impose the fiction on the stick and ignore a range of facts about it that conflict with the story. The stick is made of wood, cannot fire bullets, is not an artifact, weighs far less than any gun could, originated from a tree, and so on. Likewise, enacting our fictional ideals involves excluding information that conflicts with the content of the ideal and adding (fictional) information that 
conforms to it. Among the things one might ignore or exclude are those commitments, beliefs, values, reasons, and so on, that conflict with one's conception of a philosopher. Philosophers, one might think, are not the kind of people to skate, write music and fiction, or make bad arguments (ha!). And so these features of one's identity must be effaced or ignored while pursuing the ideal of being a philosopher. 'SN' is not-so-lightly edited and enhanced to become Fictional Ideal:

FI: $\quad$ had coffee with his wife this morning; lives in the San Diego; is married to Brett; loves art; makes music and writes fiction; loves skating; makes bad arguments sometimes; sometimes would rather watch TV than do philosophy; teaches philosophy to college students; loves thinking; enjoys considering different perspectives; relishes a good argument; loves cooking for his friends; stays up late thinking about philosophical problems; wants vast knowledge of multiple subjects; can argue any point; is aloof. ...

Because we must ignore or downplay various facts about ourselves, Velleman regards our ideals as inaccurate self-descriptions that we can enact to a fault. On Velleman's view, ideals are not just any fictional self-conception: an ideal is 'the image of another person, or a currently untrue image of oneself, that one can get carried away with enacting' (2006a: 325). The reason the notion of getting 'carried away' is essential to his theory of ideals has to do with the nature of fictional regard and the long-term task of becoming our ideal. In enacting a fictional self-image, we put ourselves out of view in order to focus on the task of enacting what we fictionally are: A participant in make-believe puts his real identity and his real relations to other participants temporarily out of mind. In order to enact his fictional identity and his fictional relations to others, he must devote his mind to the fiction.' (2006a: 321) But for this reason, the agent must systematically ignore various reasons and commitments he really has, and this invites irrationality. Getting 'carried away' is a matter of acting irrationally: 
'Toying with an idea in this fashion would be an irrational process, since it would require the agent to pretend that he didn't have commitments and reasons that he actually has' (2006b: 311). Velleman emphasizes that such irrationality is the short-term price for longer-term rationality if the person one pretends to be is a more rational kind of person. The irrationality of pretending to be, for example, a nonsmoker when you have smoked for twenty years is the price to pay for eventually becoming the more rational nonsmoker.

To be sure, Velleman does not think that action-by-ideal is necessarily irrational. Velleman thinks some exceptional ideals do not even require make-believe.

The Categorical Imperative . . is an ideal image of the will as acting only on universalizable maxims. To act out of respect for this ideal is therefore to emulate a will that acts out of respect for the very same ideal'. For this reason, 'emulation tends to rise to the level of attainment. ... To do the moral thing by emulating a moral person really is to be moral, since enacting a moral image of oneself is what being a moral person consists in (2006a: 329).

And normally when we engage in make-believe we keep in mind the fact that we are doing sowe do not lose sight of the fact that we are not what we fictionally regard ourselves as being. Velleman emphasizes that action-by-ideal, insofar as it involves a manner of ignoring our actual commitments and reasons, can be an irrational process: 'When the agent's deliberative faculty operates in this way, he becomes insensitive to considerations that are genuine reasons for him to act, and so he becomes dispositionally irrational' (2006a: 328). The thought, I take it, is that a commitment to make-believe for the sake of a personal ideal - and commit we must if we are really to be what we ideally are - amounts to a commitment to ignore some of our commitments. If you have got some commitments, rationality permits you to ignore them here and there, especially for the sake of temporary games of make-believe. But cultivating the real-life disposition to makebelieve that you do not have them is a different matter. Velleman emphasizes that 'an ideal gains 
motivational force when we identify with it' (2006a: 313), and identifying with an ideal is a matter of setting out to enact it so as to become it. Until the fictional dispositions become actual, one will have to get a little carried away and endure some irrationality. This makes action-byfictional-ideal paradigmatically irrational.

In what follows I develop a different conception of action-by-ideal—one that, I will argue, is paradigmatically rational. When we make-believe that 'I am a philosopher' is true, we systematically alter (ignore, downplay, enhance) information in our self-notion in order to enact the fiction. Our imaginative efforts are focused on the thought of being a philosopher, as we conceive of such a person, and so our grasp of the kind of person we are is modified in order to change who we actually are. An alternative is to focus our imaginative efforts on our unmodified self-notion. One way to do this is to exploit the organizational and affective power of poetic metaphor.

\section{Imagination: Fiction and Metaphor}

Imagination is a choice focus for a theory of personal ideals. Any such theory has to contend with two straightforward facts. On the one hand, our ideals have to be sufficiently unlike us to count as something we are motivated to achieve. My hunch is that this is a likely consequence of the difficulty of excellence. Our personal ideals represent a conception of excellence; excellence is difficult and therefore rare; thus, it is likely that we will be unlike our ideals. Of course, sometimes we aspire to maintain some status that we already enjoy: An excellent athlete might aspire to maintain and cultivate her status as an excellent athlete. But her aspiration here depends on the thought of failing to embody her ideals in the future, and so it depends on the thought of not being a certain way. 
But our ideals also have to motivate us. A self-image that never motivates is not an ideal - it is idle fantasy or mere wish (or perhaps depressingly accurate). But an ideal that is too remote from who we really are, one that fails to resemble us in some substantive way, will fail to move us into action - its distance will alarm rather than inspire. We need to be able to see ourselves as our ideal and envision a path from who we currently are to who we will ideally become. So we must be both like and unlike our ideals and both for the sake of motivation. How much exactly? I am not sure we can give a clear theory-independent answer - as we will see, different theories will provide interestingly different answers. In general, the sweet spot for a personal ideal is when it facilitates our imagining that we really are our ideal in a way that moves us to act, that something inside us - our motives, abilities, desires, reasons - speaks to that vision of ourselves, and all we have to do is unearth it. Imagination answers to both of these straightforward facts: it shows us what we might be and that we might be it.

The importance of the imagination here illuminates why normative thinking alone will not suffice for a theory of personal ideals. The belief or judgment that I should be one thing or another is not sufficient for having a personal ideal. I might think I should be meek and kind while being ineluctably drawn to the ideal of being irreverent. And though I am less certain of this, there is some reason to think that the thought that I should be a certain way is not necessary for having a personal ideal. Ideals essentially involve the aspirational thought that I am a certain way, and perhaps we can think aspirationally - in a way that motivates action - that we are a certain way without thinking that we should be that way. We (imaginatively, aspirationally) are. The question is what this imaginative, aspirational thinking amounts to. One can imagine the struggling art student in an aspirational state whose content is, roughly, I am a painter; painters paint; so I will paint this canvas. The thought that she should paint or that she should be a painter need not enter the picture. Although I am not wholly convinced of this line of thought, it does not seem 
unreasonable. (Much depends on further inquiry into the nature of the moral psychology of ideals, especially on what kinds of emotions are warranted by the failure to live up to one's personal ideals.)

Another way to put this point is to emphasize that personal ideals are self-images, which normative thinking alone does not capture. The thought that I should be such and such a way can just as easily capture how another person or some other part of me thinks of me, independently of what I really think about myself. Normative thinking does not make sense of the idea that self-idealization involves the aspirational thought that $I$ am a certain way while reasonably believing that I am not that way, or being agnostic about whether I am. We need to appeal to the imagination.

But one can agree with Velleman that a theory of action-by-ideal should appeal to the imagination without agreeing that it should be in the service of make-believe. This is because we might employ our imagination by way of regarding ourselves metaphorically as a certain type of person. (The following discussion draws on Elisabeth Camp's excellent 'Two Varieties of Literary Imagination: Metaphor, Fiction, and Thought Experiments' [2009] where she makes the distinction between fictional and metaphorical imagination.)

Metaphors are famously inaccurate when taken literally - so much so that most of them are absurd or categorically false. We normally cannot attribute to the speaker any belief in the literal content of the sentence uttered (however, some sentences can be meant literally and figuratively: John Donne's metaphor 'No man is an island,' is literally true, as is 'Moscow is a cold city'). When Bob Dylan says 'Chaos is a friend of mine' (Cott 2006: 50) or when Walt Whitman (2007: 8) writes, 'And your very flesh shall be a great poem,' we cannot take them at their literal word. Chaos cannot literally be a friend nor can one's flesh literally be a poem.

But the contrast to literal here is not fictional. Dylan does not accept, fictionally or otherwise, the literal content of 'Chaos is a friend of mine'. The correct interpretation of 'Chaos 
is a friend of mine' is not 'In the fiction, chaos is a friend of mine.' What he does accept, if anything - or at least what he communicates - is something about the unpredictability and lack of order in his life. Likewise, when Romeo says that Juliet is the sun, he should not be construed as accepting the literal content of 'Juliet is the sun'.

What explains this at least in part is that metaphorical interpretation lacks a feature that fictional interpretation contains. As we saw in the previous section, make-believe requires us to manipulate our conception of the object of fictional regard - we ignore that the stick is made of wood, that it is too light to be a gun, cannot be loaded, and so on. Metaphorical interpretation, in contrast, requires that we hold fixed our conception of the object of metaphorical regard, so that it can be 'filtered' or 'framed' by the metaphor.

To see this more clearly, we can juxtapose fictional and metaphorical interpretations of a single sentence.

(1) Metaphorically: Adam is a redwood.

(2) Fictionally: $\quad$ Adam is a redwood.

The natural interpretation of (1) is, roughly, that Adam is especially tall and broad. We use our conception of redwoods to 'frame' our conception of Adam (more on 'framing' in a moment). But the natural interpretation of (2) has nothing to do with Adam's height - for all (2) says, Adam may be unusually short. Instead, (2) prompts us to imagine Adam doing the things redwoods characteristically do or being the way redwoods characteristically are. He may stand on his tippy toes, push out his chest, throw his arms up, and elongate his face.

A perspectival shift or 'framing effect' (Moran 1989) is a widely noted effect of novel and poetic metaphors though there is little consensus on how exactly to understand it. Poetic metaphors draw our attention to the ways in which the focus (e.g., Juliet, Adam, your very flesh) has the character of the frame (e.g., the sun, redwood trees, a poem) in such a way that 
information about the focus is 'filtered' by our conception of the frame. The effect also tends to have a related affective character. We feel that we have better understood the focus, or that something about it has been illuminated, or that seeing it in this light is fascinating, wondrous, or intriguing, and this can affect how we treat the object of metaphorical regard (see Elisabeth Camp's [2008] illuminating discussion of poetic effect).

Donald Davidson (1978) likens the framing effect to perceptual 'seeing-as' wherein features of a scene, for example, a complex group of lines, are seen now as a duck, now as a rabbit. In the perceptual case, the concepts 'duck' or 'rabbit' are used to organize and highlight different features of the lines, drawing our attention to the lines' duck- or rabbit-like character and keying us into different affordances. Similarly, poetic metaphor causes a perspectival shift wherein our practical, affective, and theoretical perspective on the focus is organized and colored by our understanding of the frame.

Precisely how the object is framed depends on context, often on the attitude of the speaker or hearer toward the object of metaphorical regard. When we hear 'Juliet is the sun' in the context of romantic love, our attention is drawn to the ways in which Juliet has the romanticlove-relevant character of the sun: she is the center of Romeo's universe, she is the light of his life, and so on. But there are numerous ways of using the concept of the sun to metaphorically characterize an object. Consider 'Juliet is the sun' in the context of team sports - she is the leader, the player around which everyone else revolves, if you get too close she will burn you, she is a star, and so on.

In sum, understanding one thing fictionally as another requires us to alter our conception of the one so as to match our conception of the other. In make-believe we are allowed to lose sight of the focus by way of bringing a fiction to life. But for the framing effect of metaphor to work, we must hold fixed our conception of the focus. Understanding one thing metaphorically 
as another requires that we hold facts about the one thing fixed and 'filter' them through our conception of the frame so as to understand the one in terms of the other.

\section{Ideals and Metaphor}

With this characterization of metaphor in mind, consider the metaphorical interpretation of 'I am a philosopher'. An immediate objection to this points out that metaphors often involve category mistakes. 'Chaos is a friend of mine' seems to work in part because chaos cannot be a friend. Whitman's metaphor 'And your very flesh shall be a great poem' seems to work because flesh cannot be a poem. If we are to understand these statements at all, then it must be in some other way. Although this is a notable fact about many metaphors, it would be a mistake to turn this trend into a rule. Metaphors can be apt without containing category mistakes - consider 'Moscow is a cold city' or 'Ray is a real poet.' Moscow is literally a cold city, and Ray could be a poet, but there are successful metaphorical interpretations of both. Furthermore this problem, if it is one, applies only to such simple, and I think less realistic, ideals. It becomes less acute when we consider more complex ideals in section 5 (for discussion of 'twice true' metaphors, see Cohen (1976)).

As we saw with 'Juliet is the sun' there are multiple ways an object can be framed by a metaphor. When it comes to the concept philosopher, without some context we should think it might highlight one's negative philosopher-like characteristics as much as the positive - it could just as easily highlight a person's unworldly, aloof, disheveled character as her bright, sharp, erudite, fair-minded character. For 'I am a philosopher' to function as an ideal, the framing effect must have a positive upshot - it must paint the focus in a positive light. But why think that it will do so? 
I think that contemplation of our personal ideals is an expression of a kind of self-love, that the kind of evaluative regard that Romeo directs toward Juliet, when he sees her as the sun, is self-directed when we see ourselves under the guise of an ideal. As Harry Frankfurt writes:

'The most rudimentary form of self-love ... consists in nothing more than the desire of a person to love. That is, it consists in a person's desire to have goals that he must accept as his own and to which he is devoted for their own sakes rather than merely for their instrumental value.' (Frankfurt 2004: 90)

To have a personal ideal is to have just such a goal. It is to have an aim - to be a philosopher, an artist, a parent - that one accepts as one's own out of a sense of the intrinsic value of being such a thing. In this way, having and contemplating a personal ideal is an expression of self-love. The metaphor view construes this as the loving use of metaphorical self-regard. As such, the motive that inspires this kind of imaginative self-regard also tunes it to strike the right chord - ideal-selfregard is poised to highlight certain features we regard as positive.

Thus, the loving metaphorical thought 'I am a philosopher' should represent me, Nick Riggle, roughly in the following fashion (Metaphorical Ideal):

MI: had coffee with his wife this morning; lives in the United States; is married to BR; loves art; makes music and writes fiction; loves skating; makes bad arguments sometimes; sometimes would rather watch TV than do philosophy; teaches philosophy to college students; loves thinking; enjoys considering different perspectives; relishes a good argument; loves cooking for his friends; and so on.

The phrases in italics are made salient by the poetic metaphor. In this way I see myself as a philosopher in a way that might motivate me to pursue philosopher-like activities. In other words, I organize my self-notion in such a way that the respects in which I am like a philosopher 
come to the fore and are colored by my positive evaluation of being a philosopher. In seeing myself as a philosopher, I may even come to believe that I am like a philosopher in a way that further moves me to actions that prove that I am indeed like a philosopher and could even be one.

Note that this does not sling us back to the 'simple' proposal considered at the outset. On that view, action-by-ideal consists in deploying beliefs about what philosophers are like along with the desire to be a philosopher. And this can occur independently of whether one is at all like a philosopher. The metaphor view involves using metaphors to see oneself in a certain way and to draw one's appreciative attention to facts about how philosopher-like one really is in a way that moves one to do the things philosophers do. Once I see myself as a philosopher and thereby come to appreciate ways in which I am like a philosopher, other aims associated with being such a person come into view. I may reasonably think that I can become the kind of person who is always fair-minded, has vast knowledge of multiple subjects, or is able to argue any point. These features are not inserted into a fictional self-conception that I adopt - the content of my selfnotion remains the same - they are brought into view as aims, the attainability of which is suggested by the aptness of the metaphorical thought that I am a philosopher.

\section{Comparing and Contrasting}

With the fiction and metaphor views on the table, we can look more closely at how they differ. In this section I compare and contrast them along several different dimensions, selected for their potential to shed light on the rationality of action-by-ideal (which I discuss in the next and final section).

\subsection{What we accept}


On the metaphor view, contemplating an ideal need not commit me to its literal content. When I think of myself as a philosopher, under the guise of a metaphorical ideal, I need not accept the literal content of 'I am a philosopher'. This contrasts with the fiction view, according to which when we contemplate our ideals, we accept the literal content of, for example, 'I am a philosopher' only without the aim of thereby accepting a truth. But on the metaphor view, there is an associated literal truth that I may accept - that I am appreciably philosopher-like, enough, at least, for the metaphor to take hold and for me to be moved by its poetic effects in a way that brings this thought to mind.

\subsection{Ambivalence}

As a result, the views have interestingly different explanations of the ambivalence I suggested we tend to feel toward the thought of our ideal selves. On the fiction view, our ambivalence consists in the conflict between the wish that one were a certain way and the belief that one is not. I wish that I were a philosopher, but I believe I am not, and so make-believe that I am while perhaps feeling a bit uneasy about this psychological arrangement, especially if it involves being irrational or inauthentic. But on the metaphor view, 'I am a philosopher' is not something toward which we must bear the attitude of belief, 'mock' or not. So what kind of attitude do we have toward it? I am inclined to say that our primary relation to the proposition is practical or ethical. I use the thought to cause a certain effect - the framing effect of poetic metaphor - and to thereby motivate action. My relation to it is similar to my relation to something I like or love but which I know I should not love too much - given its propositional nature, that would mean regarding it as true. On the metaphor view, then, our ambivalence consists in the self-loving use of a certain thought whose literal content we cannot in good conscience accept but also cannot in good faith deny.

\subsection{Motivation}


These views also have different ways of understanding how ideals motivate action. On Velleman's view, 'an ideal gains motivational force when we identify with it' (2006a: 313). When we identify with an ideal, we draw on various 'labile motives' or 'drives' to motivate action in line with the ideal. On Velleman's view, drives are a kind of Silly Putty motive, bendable into so many shapes, toward so many ends - they are things like the motive toward aggression or love. When we identify with the ideal of boldness, for example, we might harness our labile aggressive motive and direct it toward bold action, in spite of being timid. Our various other motives that spur us to shy away, though put out of mind or kept at bay, will circumscribe our make-believe boldness so that we do not get too carried away with enacting the fiction and do things we would rather not do.

On the metaphor view, an ideal gains motivational force only when it is apt, and it is apt only when features of our real selves are highlighted by the metaphor. When, out of self-love, I see myself as a philosopher, I am moved to pursue philosophical activity. When, in seeing myself this way, I come to appreciate how I am philosopher-like, I am further motivated to turn resemblance into reality. And I am unmotivated or ambivalent to the extent that reality demurs.

But note that there is something puzzling about this. Why do metaphorical ideals move us to action, rather than console us into complacency? Perhaps I am motivated when I see myself as a philosopher, but why should I be further motivated when I notice how I am like a philosopher? After all, we might be rather pleased at the thought that we are like our ideal. Why should this not lead to idle self-congratulation? Why are we not self-flattered into indolence when the metaphor takes effect? ${ }^{17}$

\footnotetext{
${ }^{17}$ Thanks to Julia Staffel for asking me this question and for raising the objection in the following section.
} 
Perhaps this is a danger in certain cases, but often an awareness of similarity goes hand in hand with an awareness of difference. Romeo is well aware, and probably thankful, that Juliet is not a gaseous body. Likewise, when I metaphorically regard myself as a philosopher, I am not ignorant of the ways in which I am not a philosopher. This is reflected in my ambivalence toward my ideals and made evident in the fact that I have kept my self-notion unmodified and in view. The gap here is a gap to cross, if being a philosopher really is my ideal, and so the awareness of difference is a step away from a motive to action.

\subsection{Norms}

Another difference between the views concerns the restrictions they impose on which ideals we can adopt. On Velleman's view, there are almost no limits on which ideals we can adopt - an entirely ungenerous person can adopt the ideal of generosity so long as she can enact the pretense and has motives diffuse or labile enough to be cast in the relevant role.

But on the metaphor view, if the person is basically nothing like her 'ideal', then the framing effect will not occur and the metaphor will fail. By the account of motivation just given, motivation-by-ideal cannot occur. The thought can be formed into an objection to the metaphor view. In short:

(1) Someone who is utterly unlike an ideal, $I$, can nonetheless aspire to be $I$.

(2) Metaphors work only if the focus is appreciably like the frame (i.e. only if they are apt).

(3) Therefore, ideals are not metaphors.

Here, (2) is entailed by any plausible theory of metaphor, and thus the trouble, if any, lies with (1). I think that it is possible for a deeply stingy person to have as a goal being more generous, and perhaps that person morally ought to have that goal, if possible. But does it make sense for such a person to adopt generosity as a personal ideal? 
I do not think so. It is unfitting or inappropriate for someone who is hopelessly clumsy and uncoordinated (and knows it) to adopt being an athlete as her personal ideal (i.e., to aspire to be an excellent athlete). Of course, it is perfectly reasonable for such a person to take up running or join a softball team, but our ideals can be unfitting, distorted, or inappropriate. Thus, there seem to be norms governing the adoption of personal ideals, and this is something a theory of personal ideals needs to explain. If that is right, then (1) needs serious refinement.

But an appropriate refinement will be unlikely to deliver the conclusion. We would have to say something like

(1*) Someone who is utterly unlike an ideal, $I$, can within certain limits aspire to be $I$. The question then becomes: What are the limits? The metaphor view has a straightforward and substantive way of imposing such limits by understanding the normativity of ideals in terms of the aptness of metaphor. An ideal is appropriate for an individual only if it is metaphorically apt. In this way, which ideals we can adopt is, in a sense, an aesthetic matter.

It is not as clear what resources the pretense view has for explaining such norms, especially if, as Velleman emphasizes, action-by-ideal requires putting one's real self out of view: 'a participant in make-believe puts his real identity . . . temporarily out of mind. In order to enact his fictional identity. . ., he must devote his mind to the fiction' (2006a: 321). And the norms are even looser considering how, as we saw above, Velleman emphasizes the labile character of the kinds of motives that play a role in action-by-ideal.

Perhaps, then, this is one place where the fiction and metaphor views will substantially diverge - with the latter committed to there being norms of ideal adoption and the former either denying this or claiming that the norms, whatever they might be, are far less demanding than the metaphor view entails. 
But I think the biggest difference between these ways of thinking about personal ideals concerns the role each view envisions for ideals in the course of rational action.

\section{Ideals and Rationality}

People love to cite Walt Whitman's excuse for being inconsistent: 'Do I contradict myself? / Very well then I contradict myself, / (I am large, I contain multitudes)' (Whitman 2007: 67). This statement could easily make a philosopher cringe because containing multitudes is no excuse for contradicting oneself, if those multitudes are wanton alethic attitudes. In that case one should get a grip on oneself, not cite poetry. But Whitman speaks of contradicting himself, not of having contradictory beliefs. This suggests that the contradiction is not propositional but practical. The popular appeal of this passage is due, perhaps, to the fact that we all contain multitudes in another sense. We experience an array of conflicting impulses, desires, attractions, and thoughts - attractions to this career and that, to parties and quiet nights, to those people and these, to who we are and who we could be. Chaos is everyone's friend.

One way to deal with such conflict is to finesse it through fiction. Enact the image of the kind of person who speaks to your aspirational desires and commitments - bending your drives into service where possible - while dispositionally ignoring contrary reasons and commitments at the cost of short-term irrationality.

Such irrationality is a result of the factors considered above. I accept the literal content of 'I am a philosopher' as a mock-belief, that is, without the aim of thereby accepting a truth. But I wish it were true, and thus I am moved to draw on whatever motives I can muster to enact the fiction. There are almost no limits on how far I can take this activity; the only thing that can get in my way is my actual self, reminding me of my real-world reasons and commitments. So if I am 
going to have any success, I must systematically downplay or ignore these reasons and commitments. I must act on reasons I only fictionally have and against ones I really do have.

Another way to deal with inner conflict is to deploy creative metaphors. When an inaccurate self-description is a metaphorical ideal, you need not accept its literal content. The ideal helps you see yourself in a new light, provides you with a practical aim, and functions to draw your attention to ways in which the metaphor is apt. You need not ignore your real-world reasons or bend your motives and drives out of shape. In fact you must not do so if the metaphor is to take effect and highlight features of your actual self. Your attention is drawn to evidence that supports the thought that you really are like the kind of person you metaphorically are. Your real thoughts, emotions, desires, abilities, and experiences - are represented in such a way that the metaphorical thought is partly the truth.

One way to appreciate the difference here is to consider someone who is normally harsh and tough but whose personal ideal is to be kind. On the metaphor view what generates kind action-by-ideal is the person's seeing himself as kind along with his occurrent appreciation, via metaphor, of how he really is like a kind person. This can rationally motivate the tough person to be more kind by getting him to appreciate his kindness, even if it is present only in seedling form. This can result not just in real kindness but also in adding a kind tone or color to his normal tough-guy behavior, which may be rather unkind. He is not forced to ignore, disavow, redirect, or reshape the motives and attitudes that tend to produce harsh and tough behavior, as he arguably would if he were enacting the fictional role of a kind person. Better to keep those attitudes in sight so he can appreciate how his ideal of kindness modifies them. But on the fiction view, any intrusion of one role into another must be seen as a failure to properly play a role (fictional or actual) - a failure that invites us to further focus our performance and, in the fictional case, induces us to get carried away. 
The metaphor view, in contrast, describes paradigmatic action-by-ideal as rational action - a metaphorical ideal rationally motivates your pursuit of the aim it presents as attainable. Metaphorically seeing myself as a philosopher moves me to pursue philosophical activity; in doing so, I come to appreciate the ways that I am like a philosopher in such a way that the thought that I could become one is not unreasonable. I grasp that philosophers prize reason and think carefully, and, seeing myself as a philosopher, I resolve to prize reason and think carefully myself. Or consider the struggling art student who metaphorically sees herself as an artist. She is moved to pursue artistic activity and comes to appreciate the ways in which she is like an artist; she is moved to act in ways that cultivate and develop her artistic qualities. In such cases, one acts on what one regards as sound evidence about what one is like, evidence that comes to light via metaphor - and then one sets out to pursue related activities or take up related commitments and values.

Of course, Juliet's regarding herself metaphorically as the sun and thereby appreciating the ways she is sun-like, does not give her reason to, say, try to activate photosynthesis in a plant with her mere presence. No matter how sun-like she is, she will never be the sun. But she will also never aspire to be the sun - something it is metaphysically impossible for her to be - at least if she is rational. Our metaphorical ideals present ways of life that we have no conclusive reason to think we could not live, and via metaphor they get us to appreciate the thought that we could.

The irrationality of action-by-fictional-ideal is compounded and the virtues of action-bymetaphorical-ideal amplified when we consider the fact that our ideals are usually far more complex than the ones we have been considering, because the 'multitudes' they harness tend to be so vast. Thus far we have been considering artificially thin personal ideals - ones that have a single descriptive dimension like 'is a philosopher'. But many who go in for thought and action by ideal have more nuanced, creative, robust, or individualized personal ideals. We do not 
always act from a particular conception of our ideal self as specifically a philosopher or artist, but from a holistic sense of who we ideally are - a sense of self that we cannot always easily formulate in words and that we might naturally express by simply using our proper name. In an aspirational spirit, I might just think I am Nick Riggle! Perhaps more often than not when we reflect on ourselves under the guise of an ideal, we do so in this holistic manner. I might be faced with one of those rare wide-open days, able to do as I please; I might be at a personal crossroads, unsure of where or how I should direct my life; I might be amped up, animated by the thought of the vague many things I might become. In these cases I might think I am Nick Riggle in a holistic, gestalt-like, and motivating manner.

If I were to say something more specific about my own ideal self, I would list a variety of things. On a good day, I might say that I am a philosopher, husband, creative person, loving person, skater, writer, musician. These different dimensions of my ideal self speak to different aspects of who I really am or have been - different impulses I have nurtured and explored, different desires I experience and express, different experiences I want to cherish and relive, different projects and activities I love.

How can the fiction and metaphor views make sense of these more creative and realistic ideals? The metaphor view can associate a proper name with a set of metaphors. We can think that Nick Riggle is [a philosopher, husband, creative person, loving person, skater, writer, musician]. In this way, the thought I am Nick Riggle might be an expression of self-love, not a boring statement of obvious fact. Elements of my self-notion are holistically selected and organized by the concept NIGK RIGGLE:

MI*: $\quad$ had coffee with his wife this morning; lives in the San Diego; is married to Brett; loves art; makes music and writes fiction; loves skating; makes bad arguments sometimes; sometimes would rather watch TV than do philosophy; teaches 
philosophy to college students; loves thinking; enjoys considering different perspectives; relishes a good argument; loves cooking for his friends; and so on.

In this way the metaphor view can make sense of the holistic thought that I am Nick Riggle as the thought of something I can fall short of or achieve - where being myself is metaphorically being my holistic ideal self. And maybe the phrases not in italics could also be selected by my complex ideal: An excellent partner would rather watch TV than work into the evening; perhaps a creative person would delight in making wild connections between thoughts.

Of course, on both the fiction and metaphor views the thought I am Nick Riggle abstracted from any particular context is poised to highlight a range of conflicting aims that I cannot jointly pursue at any given moment. But this is rarely a problem because a practical context will suffice to make some aims more salient than others. On the metaphor view, just as 'Juliet is the sun' functions differently in the contexts of romantic love and team sports, so I am Nick Riggle functions differently if I am at the skate park or in the classroom. The fiction view can similarly rely on context to tone down, collect, or focus a complex ideal's many ambitions or aims.

But it is not easy to see how the fiction view can capture the holistic character of the thought that I am Nick Riggle. For the fictional thought that I am a philosopher keys me into a mode of thinking that threatens to conflict with the modes of thought of whatever else might feature in a complex personal ideal. When we pretend to be a philosopher, we draw on and act from our concept of a philosopher while effacing aspects of ourselves that may conflict with doing so. This positions one to think, act, and generally self-conceive in philosopher-like ways that may conflict with thinking and acting from the image of a creative person or a skater. As a result, there appears to be no coherent fictional character who is, in a holistic sense, all of the many things that one might include in one's complex personal ideal. Therefore, it is difficult or perhaps impossible to conceive, in a synthesizing, holistic way, of a fictional character who is, at once, a 
philosopher, husband, creative person, loving person, skater, writer, musician. Thus, the fictional thought that I am Nick Riggle, insofar as it is shorthand for a collection of conflicting fictions I am disposed to enact, cannot be grasped in a holistic way. At best I can think in terms of practically and theoretically coherent proper subsets of my personal ideal.

Another way to think about this problem is to think of fictional characters as roles in fictional narratives and try to make sense of the character's narrative. What would it be? It is difficult to conceive of a single narrative about such a multitudinous character. What would the guiding theme be? Where would we locate the narrative arc? What would count as a good ending? We cannot answer these questions, and so we cannot get a grip on what such a fictional character would be. Furthermore, even if we could answer these questions and construct some fictional character and accompanying narrative, I doubt it would be a character anyone would want to be or a story anyone would want to tell about themselves. In other words, it would not be an ideal.

No analogous problem arises on the metaphor view because the self and life that the metaphor I am Nick Riggle picks out is my actual self and life, with its conflicting desires and demands. Where the fiction view runs into problems of literary coherence, the metaphor view exploits the richness of poetic invention. The metaphor I am Nick Riggle, insofar as it is composed of apt metaphors, holistically illuminates a multifaceted thing; the fiction I am Nick Riggle picks out a multitasked and overburdened thing that, by my own lights, I cannot be. (Thus the metaphor view makes clear room for holistic positive self-conceptions for individuals who are devoted to communities with divergent values.)

And if I cannot grasp my ideal self in a holistic way, then I cannot be motivated by the holistic thought that I am Nick Riggle. It would seem, then, that the fiction view would have to regard acting from a holistic sense of our ideal selves as a matter of attempting to be something 
that, by one's own lights, one cannot be - and this would be as irrational as Juliet attempting to be the sun. On this view it would seem that one can never rationally aim to be oneself, insofar as one identifies with one's complex ideal self, grasped holistically.

On the fiction view becoming who one ideally is would require a more piecemeal effort, pretending to be one thing and then moving on to the next. But on the metaphor view, I become who I ideally am as the metaphor dies and becomes literally true. If we ever become who we ideally are, then the various terms that feature in our ideals, such as 'is a philosopher,' will become normal predicates, used to speak and think the regular truth. The birth of who you ideally are would be, in a sense, the death of poetic metaphor.

But I am beginning to think that the metaphors never really die; perhaps we are always becoming who we ideally are. If our more creative and individual ideals are as complex as I have suggested they are, then it seems that we will always be toying with the idea that we are what we ideally are. But to toy with an idea in this fashion is not to invite irrationality, for it is a way of seeing aspects of who we really are-bundled for appreciation by the metaphors that make up our ideal self-conceptions - in the light of who we ideally are.

One remaining question is whether, all things considered, one view is superior to another. Although I have pointed out some appealing features of the view that ideals are metaphors, we are not yet in a position to take up this question, and more work needs to be done on the ethics, moral psychology, and aesthetics of personal ideals. No doubt people can exploit both modes of inaccurate self-description, and each has its advantages. Here I have focused on two ways in which we use our imagination to become who we aspire to be, both of which are reasonably considered action-by-ideal. Understanding ideals as metaphors provides us with an interesting and plausible alternative to Velleman's thought that ideals are fictional self-conceptions. And if 
what I have argued is right, then there is a limited contrastive case for the view that personal ideals are metaphors.

A significant issue turns on whether we should think of action-by-ideal as paradigmatically rational. If we should, then it is a strong point in favor of the view of ideals as metaphors that it can be rational in the short and long term to enact an image of a self I am not - the self I metaphorically am, the quasi-poetic self-image I have cobbled together. It is this image that gives me a gemlike, multifaceted, positive perspective on who I am and what I am doing with my life, and in so doing grounds a range of rational actions the ideal makes available. And we all know that philosophers are nothing if not aspirationally rational. I guess that means that, in pursuing my ideal of being a philosopher, I am a bit like a philosopher. And that in turn makes me a bit like Nick Riggle. Good thing. I have always wanted to just be myself. 19, 20

19 This paper is written to stand on its own, but it is also part of a larger project that investigates whether there is a defensible conception of 'aestheticism', or the view that aesthetic value can be the overarching value of a good life. The view I develop emphasizes the importance of (and connections between) the aesthetic phenomena of style, beauty, metaphor, and interpersonal appreciation. In my paper 'Personal Style and Artistic Style' (Riggle 2015a) I argue that personal style is a matter of embodying one's ideals, and in my paper 'On the Interest in Beauty and Disinterest' (Riggle 2016) I suggest that beauty is the expression of personal ideals. Putting these ideas together: having style is a matter of making oneself beautiful, by one's own lights, which is a matter of crafting and embodying a poetic self-conception. For another part of the project, see my paper 'On the Aesthetic Ideal' (Riggle 2015b).

20 Thanks to the organizers and participants of the 2014 Rocky Mountain Ethics Congress (RoME) and to Julia Staffel for her excellent comments. Thanks to the attendees and organizers of the 2015 American Society for Aesthetics Annual Meeting and to Brian Soucek for very helpful discussion and feedback. Thanks to Jonathan Cottrell and the Wayne State Philosophy Department for a great discussion. Thanks to my colleagues at the University of San Diego for comments, discussion, and encouragement. And I am grateful for the time and attention of two anonymous referees whose comments improved the paper. 
Nick Riggle

University of San Diego

nriggle@sandiego.edu 


\section{References}

Anderson, Elizabeth. (1993) Value in Ethics and Economics. Harvard University Press

Camp, Elisabeth. (2008) 'Showing, Telling, and Seeing: Metaphor and Poetic Language.'

The Baltic International Yearbook of Cognition, Logic and Communication, vol. 3: A Figure of Speech, 124.

Camp, Elisabeth. (2009) 'Two Varieties of Literary Imagination.,' Midwest Studies in Philosophy, $33,(107-30$.

Callard, Agnes. (2016) 'Proleptic Reasons.' Oxford Studies in Metaethics, vol. 11.

Cohen, Ted. (1976) 'Notes on Metaphor.' Journal of Aesthetics and Art Criticism, 34, 249-59.

Cott, Jonathan. (2006) Bob Dylan: The Essential Interviews. Wenner.

Davidson, Donald. (1978) 'What Metaphors Mean.' Critical Inquiry, 5, 31-47.

Fischer, Jeremy. (2012) 'Being Proud and Feeling Proud: Character, Emotion, and the Moral Psychology of Personal Ideals.' Journal of Value Inquiry, 46, 209-22.

Frankfurt, Harry. (2004) The Reasons of Love. Princeton University Press.

Moran, Richard. (1989). 'Seeing and Believing: Metaphor, Image, and Force.' Critical Inquiry, 16, 87-112.

Riggle, Nick. (2015a) 'Personal Style and Artistic Style.' The Philosophical Quarterly, 65, 711-31.

Riggle, Nick. (2015b) 'On the Aesthetic Ideal.' British fournal of Aesthetics, 55, 433-47.

Riggle, Nick. (2016) 'On the Interest in Beauty and Disinterest.' Philosophers' Imprint, 16, .

Velleman, David. (2000) 'On the Aim of Belief.' In Velleman, The Possibility of Practical Reason (Oxford: Oxford University Press), .

Velleman, David. (2006a) 'Motivation by Ideal.' In Velleman, Self to Self (Cambridge : Cambridge University Press) . 
Velleman, David. (2006b) 'Willing the Law.' In Velleman, Self to Self (Cambridge: Cambridge University Press), .

Velleman, David. (2006c) 'Identification and Identity.' In Velleman, Self to Self(Cambridge:

Cambridge University Press), .

Whitman, Walt. (2007) Leaves of Grass. Dover. 